\title{
EL DESTIERRO COMO MISERIA METAFÍSICA EN "NOS HAN DADO LA TIERRA" DE JUAN RULFO
}

\section{THE DEBATE AS METAPHYSICAL MISERY IN "THEY HAVE GIVEN US THE EARTH" BY JUAN RULFO}

\author{
José Luis Petrikowski Escobar \\ UNIVERSIDAD AUTÓNOMA DE CHIAPAS
}

Si bien la creación literaria de Juan Rulfo es de una brevedad evidente -la conforman únicamente El llano en llamas y Pedro Páramo-, ésta ha sido de las más comentadas a partir de la segunda mitad del siglo $X X$, sobre todo en el ámbito de la literatura nacional. A través de los textos surgidos en la crítica literaria y el periodismo cultural, podemos percatarnos de la fuerza de interpelación que las narraciones de Rulfo logran en los lectores y críticos de todo nivel del ámbito de la valoración literaria. Todo esto obedece, evidentemente, a la calidad de esta obra, por lo que se tienen siempre comentarios favorables y el intento de profundizar en muchas dimensiones (temática, estética, hermenéutica, narratológica, retórica) de la misma: la realidad del universo de escritura rulfiano se sustenta en algo que escapa a la homologación de Rulfo con su época y su contexto literario; es más, los sobrepasa, no obstante que El llano en llamas y Pedro Páramo, se puede afirmar, cierran el ciclo de la narrativa de la revolución mexicana y de sus tópicos aledaños. Por ello, Juan Rulfo es un punto de referencia obligado en el espectro de la literatura mexicana y continental que trasciende a planos más amplios: la literatura mundial.

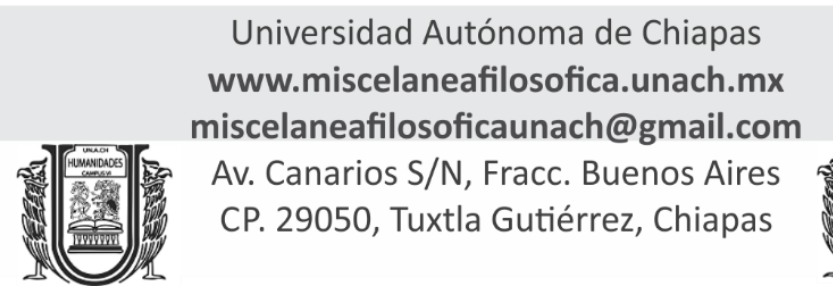


| Cuatrimestral Facultad de Humanidades Campus VI

Reserva de Derechos al Uso Exclusivo No.: 04-2018-060814012200-203 | ISSN: 2594-1755

Año II | Número 5 | Enero- Abril 2019

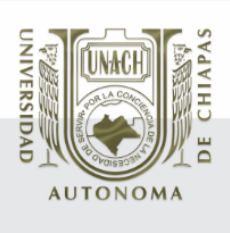

\section{ARTÍCULOS}

Los cuentos y la novela de Juan Rulfo han sido lectura obligada para aquellos que toman la literatura desde una postura lúdica, para quienes se forman en el estudio de la literatura de forma más académica, y también para quienes se dedican al quehacer literario de forma profesional. No obstante que se aborde su obra en cualquiera de estos tres niveles, seguramente que todo lector (crítico) de los textos de Rulfo descubre que en su universo narrativo confluyen el mundo de una realidad que hemos percibido de forma constante, la realidad del ser humano latinoamericano con sus pobrezas, sus miserias, con un mundo que está más allá de nuestras percepciones ordinarias, un mundo mítico y primigenio, pero que guarda estrechos nexos con aquella realidad tangible; es decir, el mundo de la obra de Rulfo posee una significación en la que la confluencia realidad/irrealidad dan a las instancias de los personajes, acontecimientos y espacios una perspectiva que puede ser interpretada como la imbricación de lo tangible e inmediato (mundo material, social y cultural) con un mundo intangible, etéreo (mundo de la esperanza o desesperanza) que a veces puede ser percibido como reflejo y, quizá, trascendencia del primero. Esta es la visión del mundo rulfiana, la imago mundi que se plasma como constante en muchos de sus relatos.

"Nos han dado la tierra", cuento perteneciente a El llano en llamas, permite abordar un análisis que hace factible percibir ese punto de intersección entre esos dos mundos ya señalados, el de la perspectiva temática que involucra el problema social de Latinoamérica de la pobreza, la miseria, la injusticia, y aquel que se refiere a una miseria más trascendente que se expresa en una forma de desarraigo, destierro humano. De esta manera, el mundo del texto literario de Rulfo, su temática, personajes, espacio y tiempo estarán en la posibilidad de análisis a partir de que

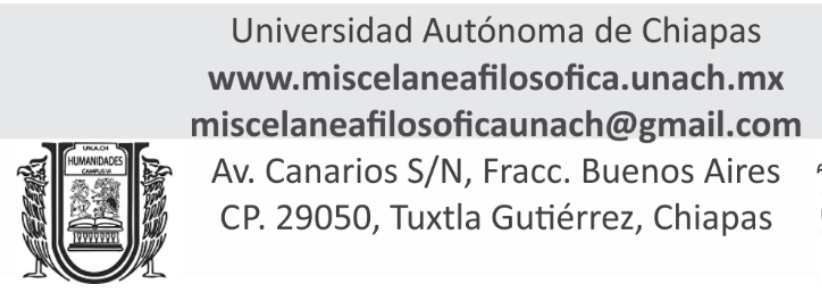


puedan ser asumidos los supuestos de mayor profundidad que la obra posee y que desembocan en los grandes temas que preocupan y ocupan al ser humano a través del tiempo. Se trata, entonces, de profundizar, a través de esa apelación-respuesta que se establece entre la obra y el lector, y trascender todo lo que la superficialidad de lo inmediato nos proporciona.

\section{El destierro como miseria metafísica}

Partimos de la idea de que esa imago mundi que el ser humano posee representa una situación concreta que puede ser localizada en el tiempo y en un lugar preciso, pero que, a la vez, experimenta una forma de separación de sí mismo, una desconexión de su ser y de su identidad. El hombre, así, se convierte en un exiliado, un desterrado de su propia conciencia. Absorbido por su entorno es, en consecuencia, un ser abatido, plétorico de ansias y frustraciones. Es decir, nos encontramos con el ser humano ciudadano del mundo exterior $\mathrm{y}$, al mismo tiempo, ciudadano de un mundo interno o de un ámbito que no está al alcance de nuestros sentidos.

La literatura se presenta muchas veces como una vía de introspección. Por ello, nos percatamos que la gran literatura siempre hunde sus raíces en los grandes temas que han cuestionado al ser humano de todos los tiempos. Toda obra trascendente es encarnación de los aspectos más profundos de la existencia (López Quintás, 1983: 61), por ello, el sentido de la vida, la muerte, la libertad, el amor, la pasión, la justicia, etc.

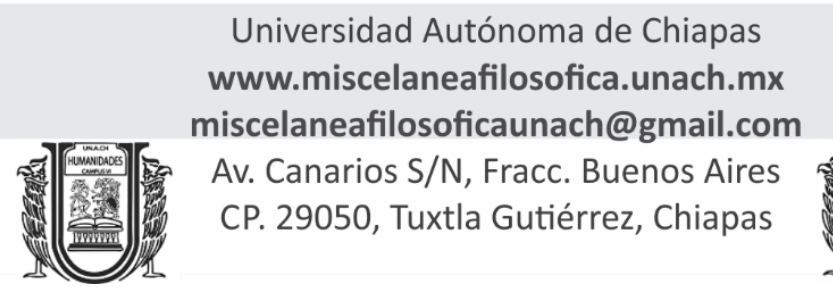


| Cuatrimestral Facultad de Humanidades Campus VI

Reserva de Derechos al Uso Exclusivo No.: 04-2018-060814012200-203| ISSN: 2594-1755

Año II | Número 5 | Enero- Abril 2019

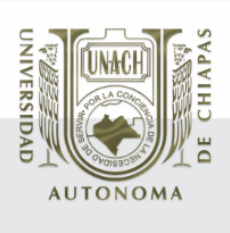

\section{ARTÍ́CULOS}

"Nos han dado la tierra", primer cuento de El llano en llamas, describe el regreso de un grupo de campesinos a su lugar de origen, después que un delegado gubernamental les informa el resultado de una gestión burocrática sobre tierras cuestión que no se narra de forma directa en el texto, sino como diálogo. La acción podría ubicarse, cronológicamente, en los primeros años de la pos-revolución mexicana:

Y por aquí vamos nosotros. Los cuatro a pie. Antes andábamos a caballo y traíamos terciada una carabina. Ahora no traemos ni siquiera la carabina.

Yo siempre he pensado que en eso de quitarnos la carabina hicieron bien. Por acá resulta peligroso andar armado. Lo matan a uno sin avisarle, viéndolo a toda hora con "la 30" amarrada a las correas... (Rulfo, 1953: 14-15)

El texto es una reflexión consciente y crítica acerca del agro mexicano, a partir de la ejecución de un mandato en el que se "dota de tierras" a ese grupo de hombres. Pero, sobre todo, el texto es representación de una vida difícil y dramática que surge de la visión de un ámbito o mundo específicos. Por ello, la tipología de los personajes de "Nos han dado la tierra" no comprende seres que se distingan por una actitud protagónica a partir de virtudes o valores, sino hombres en los que la ignorancia, la injusticia, la miseria, la segregación o el aislamiento se convierten en una realidad de vida. Busca en el interior de los hombres del campo lo que emana de esa realidad, y denuncia, con palabras directas, ambientes y seres que no se conciben como emanados de un movimiento que se propuso la justicia para todos. Los personajes de "Nos han dado la tierra", a través de diálogos alejados de toda reflexión que pudiera concebirse como eminentemente intelectual, nos presentan hechos breves y

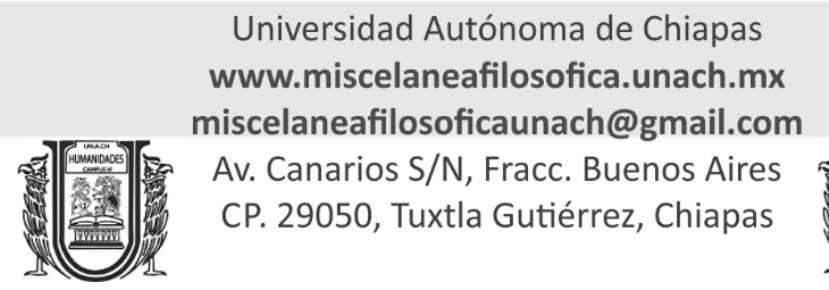


concretos, reveladores, y que, de alguna manera, proyectan una forma de acusación implícita derivada de una condición de desamparo.

\section{La miseria física y la injusticia}

La obra de Juan Rulfo plasma la problemática latinoamericana en la perspectiva de la miseria, la injusticia, la segregación y el abandono. Afirma Eduardo Galeano que América Latina es la región de la venas abiertas: “Para quienes conciben la historia como una competencia, el atraso y la miseria de América Latina no son otra cosa que el resultado de su fracaso" (Galeano, 1971: 2-3). Ese fracaso es, en el caso de nuestro cuento, el de una revolución traicionada, que se traduce, también, en una traición que se perpetra en contra de campesinos que, como respuesta a la petición de la concesión de tierras, reciben el páramo inmensurable, al mismo tiempo que inservible.

En un nivel subtextual, afirma Reis que existe un principio de base en la creación literaria que la sociología de la literatura postula: el principio de que el escritor transporta una creación colectiva. Así, dentro de un determinado contexto social, político y económico, sustentando con ese contexto vínculos y afinidades variablemente detectables, integrado en una clase social cuya problemática interpreta, el escritor es "coaccionado", de manera un tanto invisible pero eficaz, a una forma de proyección que lo lleva, muchas veces sin darse cuenta de ello, a proyectar en el texto que elabora todo el conjunto de fuerzas de raíz sociológica que subyacen en ese texto (Reis, 1989: 90).

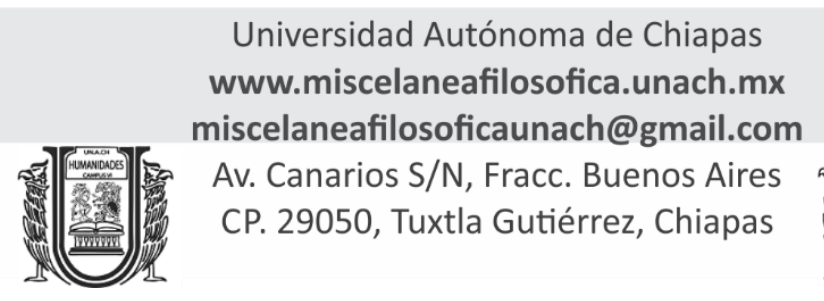


A partir de lo anterior, es posible afirmar que Rulfo es un heredero de la novela de influencia revolucionaria que parte de Azuela; pero, sobre todo, su pensamiento y su creación se ubican en la perspectiva que podría denominarse 'hispanocriolla', común a los escritores del siglo XX, y que aborda de manera muy similar los problemas más acuciantes de nuestra parte subcontinental. Por ello, los ambientes de Juan Rulfo, entre ellos el de "Nos han dado la tierra", que inician por una ubicación de los ámbitos de México llenos de desorden, arbitrariedades, violencia, muerte, pueden ser trasplantados perfectamente al ámbito latinoamericano, pues si bien este entorno se constituye a través de naciones, de divisiones territoriales, muchas veces en pugna, también éste guarda analogías que estrechan profundamente las historias de estas zonas fragmentadas:

Rulfo sabe que el padre es la ley que opera en sí mismo, y se manifiesta a su vez en el caciquismo regional, estatal, nacional, de América y del mundo". La conciencia histórica se hace una con la conciencia íntima" (Jiménez de Báez, 1990: 33)

El ambiente rural es sumamente representativo en Rulfo; por este motivo, el medio citadino es casi inexistente en su obra, ya que, se deduce, no es este medio el propicio para manifestar los verdaderos problemas y el ser del pueblo, de la gente y de los ambientes descritos en el texto. 
Se hace evidente que para Rulfo existe una relación entre literatura y mundo. Como lo afirma José Emilio Pacheco, la literatura no puede ser vista únicamente en su dimensión lúdica, sino también en su facultad de otorgar certezas de un mundo que se han diluido por diversas expectativas. De esta manera, el conocimiento de la humanidad puede darse a través de los libros, pues conocemos cómo viven otros seres humanos que sufren y gozan de manera análoga a uno mismo.

Por esa certeza del mundo, entonces, en los argumentos de El llano en llamas el estado, la ley y sus representantes se muestran de manera completamente negativa. En "Nos han dado la tierra", se narra claramente la actitud de un funcionario gubernamental que realiza el trámite para la obtención de tierras y lo único que ejecuta es un acto completamente arbitrario e injusto que redundará en más pobreza para los afectados de este reparto:

-Pero, señor delegado, la tierra está deslavada, dura. No creemos que el arado se entierre en esa como cantera que es la tierra del llano. Habría que hacer agujeros con el azadón para sembrar la semilla y ni aun así es positivo que nazca nada; ni maíz ni nada nacerá.

-Eso manifiéstenlo por escrito. Y ahora váyanse. Es al latifundio al que tienen que atacar, no al gobierno que les da la tierra". (Rulfo: 16)

Pero, además, Rulfo es alguien que retrata y plasma a través de imágenes vivas -en medio del polvo que se levanta en la aridez- lo que es su visión inmediata del mundo: yermos, polvaredas, plagas, insolaciones, vida de menesterosos que, además de la pobreza, tienen que soportar las pestes, fatigas y desesperación (Harss, 
2003: 71). Y esta es, precisamente, la visión que se tiene en "Nos han dado la tierra", donde el engangrenamiento de tierras agostadas provoca miserias que han abierto llagas: "Y a la gota caída por equivocación se la come la tierra y la desaparece en su sed" (Rulfo: 14). Por ello, escenario y paisaje en el cuento rulfiano no son ámbitos completamente diferenciados, toda vez que uno y otro son porciones del mundo en los que el ser humano deambula, muchas veces, -como en la narración-, de manera un tanto indiferente. Si el mundo es un espacio predominantemente social, en el que se da la manifestación del ser humano y sus representaciones, sus interrelaciones con otros seres similares, en la obra del escritor jalisciense ese mundo también es el páramo agreste en el que el hombre no tiene cabida.

\section{El mito en la obra y el destierro como miseria metafísica}

Pese a que, como se ha mencionado, los personajes del cuento son gente pobre, la identidad o el carácter de los personajes rulfianos no se circunscriben estrictamente a esta característica. Realmente, los personajes del cuento, y de casi toda su obra, son trágicos, ya que están predestinados para la frustración y la falta de sentido de la vida; es decir, su misma miseria es parte de la inexorabilidad del destino. De aquí que es una constante en Rulfo el trascender la realidad inmediata -quizá podríamos decir social de la obra- para ubicarnos en otra.

El texto posee un nivel profundamente mítico al asumir una realidad que está más allá de la realidad perceptible -una forma de hiperrealidad-, y que nos ubica en un modelo cultural que hace referencia al desarraigo, destierro y desamparo, común

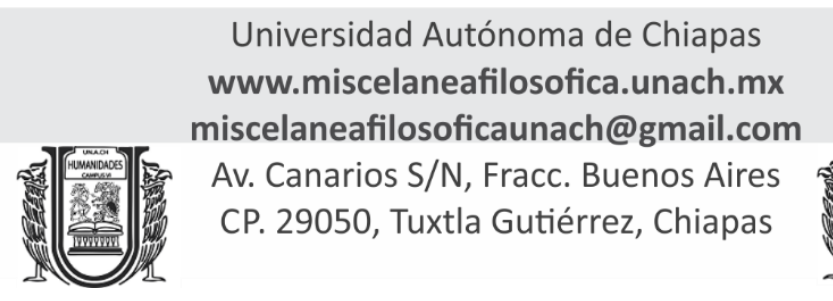


a América Latina y a todo hombre. La construcción idiomática y las inflexiones de la lectura nos sitúan en el campo mexicano, pero la temática de la obra es de tipo universal, ya que, si bien en la narración la entrega de tierras denota una forma más de injusticia y simulación, de subyugación y desprecio a estos hombres y su pobreza, la figura que se establece, como una ironía reflexiva, es una forma de peregrinaje que no tiene un punto de partida -parecería que estos hombres no provienen de ninguna parte-, así como que el punto de destino no existe; por ello la atmósfera del yermo y del vagar -más que el caminar- de los campesinos. Y todo esto conlleva esos niveles de profundidad que nos sumergen en ese destino, en el que la miseria humana es desesperación, autodevaluación, miedo, crueldad, culpa, deseo de perdón y soledad, como constantes existenciales. Al respecto, dice Monsiváis que los personajes de Rulfo se muestran dentro de un ámbito de trivialidad radical y de su soliloquio amargo que evoca continuamente el momento en el que se les trituró para siempre. Por ello, desaparecido el evento y trasfondo épico de la Revolución y el pueblo en armas, los personajes se convierten en algo complejo, por lo que son lo mismo y son algo distinto por entero, ya no seres unidimensionales, sino cuerpos frágiles y fragmentos de voces que resultan modos de ejercer la conciencia y el desaliento.

Es evidente que la idea del destierro y la indigencia metafísica no es una idea original de Rulfo, pues el modelo del éxodo, destierro y carencia proviene de literaturas antiguas; ejemplo de ello podemos encontrar en lecturas del Génesis bíblico, por lo que se establece una forma de intertextualidad: 
Al hombre le dijo:

$<$ Por haber escuchado la voz de tu mujer y comido del árbol del que Yo te había prohibido comer: Maldita sea la tierra por tu culpa. Con fatiga sacarás de ella tu alimento por todos los días de tu vida ( ) Con el sudor de tu frente comerás el pan hasta que vuelvas a la tierra, pues de ella fuiste sacado. Porque eres polvo y al polvo volverás>

( ) Por ello lo echó de la tierra del Edén, para que trabajara la tierra de donde había sido formado. (Génesis, 3: 17-24).

Tenemos quizá en esta lectura el ejemplo más primigenio de lo que es una forma de condena -a partir de un acto de desobediencia- que impone un destino inexorable al ser humano para ser un errante en su propio mundo y, además, enfrentarse a la tierra de ese mundo, la que se resistirá -pues ello implica una lucha- para otorgar los frutos que el hombre necesita.

En El Llano en llamas la relación entre el hombre y la tierra se presenta con una analogía del relato bíblico, pues esta última se constituye en el objeto deseado por el ser humano, pero sin que rinda sus frutos; entre la resistencia parcial de la tierra a dar alimento del Génesis y la total negación del relato rulfiano, existe el establecimiento de una lucha constante que se prolongará por siempre y que limitará al ser humano a satisfacerse plenamente.

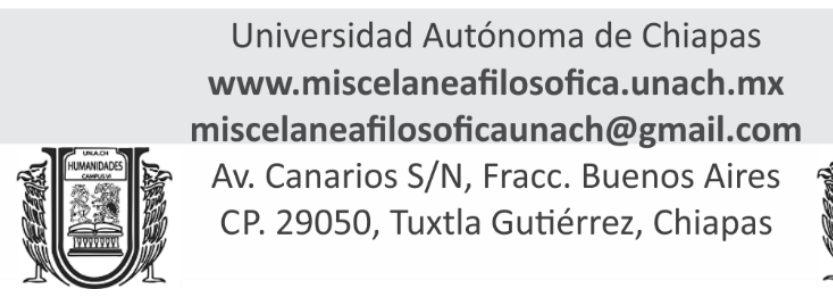




\section{ARTÍCULOS}

La figura del destierro y la miseria metafísica se dan a partir de que el hombre es expulsado del Edén -lo que puede entenderse como una forma sedentaria de vida-, donde los frutos de la tierra se dan en abundancia y sin mediar el trabajo. Entonces, la vida del ser humano se comprende como un alejamiento de lo divino en el sentido religioso- o de todo aquello que ordena la vida del ser humano; es decir, el hombre es expulsado de una forma primigenia de vida que lo convierte en expulsado de su paraíso terrenal, errante en una tierra hostil y condenado a perpetuar un conflicto con su ámbito vital. Tenemos, así, una miseria que se comprende como resultado del enfrentamiento del hombre con su mundo -y que sería lo más próximo a la miseria física-, pero también un mito adherido al ser del hombre que se constituye en sino, y que lo convierte en indigente perpetuo al poseer una esencia que rechaza de manera inherente la felicidad y la armonía con ese mundo: contradicciones y sufrimiento acompanan la vida del ser humano. $Y$, en este sentido, la misma muerte, tanto en el Génesis como en la obra de Rulfo, puede interpretarse como una forma de castigo; no es la entrega final y personal a Dios, en la perspectiva religiosa, ni la unidad final con el cosmos, en el sentido filosófico, en las narraciones de Rulfo -caso concreto el de Pedro Páramo- sino un misterio de miedo y de inseguridad.

En la historia de "Nos han dado la tierra", el destierro -no tener tierra y peregrinar por una tierra que no es la propia- se presenta como una fatalidad. Es un destierro homologado al destierro permanente de todas las culturas y de la humanidad misma. Si bien nuestro nivel superficial nos hace percibir el problema concreto de la pobreza, del agro y la injusticia en México y Latinoamérica, un nivel más profundo de lectura nos remite a cualquier historia individual o colectiva del 
hombre. Somos errantes eternos en busca del paraíso perdido, del Edén despojado; quizá allí la respuesta a nuestra inconmensurable inconformidad, a ese deseo perpetuo de anhelar lo no poseído. Y, por ello, existe una complejidad en la temporalidad descrita en el cuento, ya que si bien hay un tiempo 'real' y acotado que se refleja en el caminar de los campesinos, también hay un tiempo interminable que se proyecta en ese mismo caminar que no encuentra un destino.

Así, tenemos que el cuento de Rulfo, sustenta, como otras obras literarias, un mito fundamental de algunas culturas y del pensamiento humano: el del paraíso perdido:

Nosotros paramos la jeta para decir que el llano no lo queríamos. Que queríamos lo que estaba junto al río. Del río para allá, por las vegas, donde están esos árboles llamados casuarinas y las jaraneras y la tierra buena. No este duro pellejo de vaca que se llama el llano. (Rulfo, 15)

Lo que se hace en el texto de Rulfo, al igual que en esa literatura citada, es realizar la imagen del hombre y su condición, casi su naturaleza, de exiliado, e interpretar esta historia como una metáfora de la condición humana, en el sentido de que el hombre es un expulsado de su naturaleza original. El ser humano ha sido desterrado hasta de sí mismo y, perdido, recorre simulación de caminos, angustiosas veredas laberínticas repletas de incertidumbre:

Después de tantas horas de caminar sin encontrar ni una sombra de árbol, ni una semilla de árbol, ni una raíz de nada, se oye el ladrar de los perros.

\section{(...) ¿Quién diablos haría este llano tan grande? ¿Para qué sirve, eh?}


Hemos vuelto a caminar, nos habíamos detenido para ver llover. No llovió. Ahora volvemos a caminar. Y a mí se me ocurre que hemos caminado más de lo que llevamos andado." (Rulfo, 13-14)

Contrario al paraíso, en la naturaleza descrita por el texto, el llano es algo inútil; es páramo, no hay nada; es pendiente separada de la tierra que se ha abandonado y que solamente emerge en algunos momentos como recuerdo; es tierra siempre hostil.

Tenemos, entonces, en “Nos han dado la tierra” una búsqueda de lo esencial, subyacente a los hechos, y que nos permiten llegar a lo universal.

A partir del recorrido de regreso que hacen los cuatro campesinos -después de ser más de veinte- a su lugar de origen, es posible establecer un modelo cianótico que refuerza la condena al ser humano -a partir del Edén perdido- al destierro y a la dispersión, más que al éxodo -quizá no sea gratuita la descripción del páramo- y le evita permanecer en un lugar paradisíaco y poder así aspirar a la felicidad que se supone le es inherente ${ }^{1}$

Asimismo, un aspecto mítico que nos lleva a la profundización del modelo de la muerte, la pérdida de identidad y falta de solidaridad es el hecho de que en ese peregrinar, los hombres se van quedando solos:

\footnotetext{
${ }^{1}(\quad)$ <Por lo tanto, maldito serás, y vivirás lejos de este suelo fértil que se ha abierto para recibir la sangre de tu hermano, que tu mano derramó. Cuando cultives la tierra, no te dará frutos, Andarás errante y vagabundo sobre la tierra> (Génesis, 4: 10-12)
}

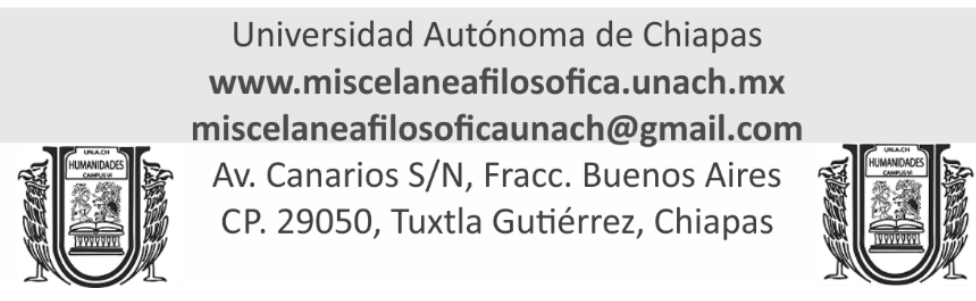


Ese alguien es Melitón. Junto con él, vamos Faustino, Esteban y yo. Somos cuatro. Yo los cuento: dos adelante, otros dos atrás. Miro más atrás y no veo a nadie. Entonces me digo: "Somos cuatro". Hace rato, como a eso de las once, éramos veintitantos; pero puñito a puñito se han ido desperdigando hasta quedar nada más este nudo que somos nosotros. (Rulfo, 13)

Entonces, tenemos que la antigua condena vetotestamentaria sigue vigente en la narración de Rulfo: es evidente que los campesinos no han rechazado el mandato de algo o alguien que se considere trascendente, como tampoco han asesinado a su hermano, pero la condena es generacional: la tierra se agosta, se hace pobre como ellos y eso supone una búsqueda incesante, que únicamente tiene como destino la soledad y la muerte. No obstante, parecería que el cuento no tiene un fin, nunca termina, pues los personajes caminaran de manera persistente hacia un punto situado 'arriba' que nunca, jamás encontrarán. Mientras, el yermo de la desolación se prolonga indefinidamente.

Teniendo como marco los ambientes descritos, en la obra de Rulfo los personajes oscilan entre lo concebido como realidad y aquello que se sumerge en lo impalpable, en lo mítico y un tanto etéreo; por ello, quienes deambulan en estas narraciones pueden percibir la tierra como algo tangible al mismo tiempo que inconmensurable, lo que provoca una visión subjetiva del mundo. Por ello, existe un enfoque interior de la realidad. En El llano en llamas, específicamente en "Nos han dado la tierra", hay una quietud agobiante en un medio casi onírico y en un tiempo suspendido, estacionado en un tiempo mayor, universal: hay una negación de la 
exterioridad concreta y se diluye la realidad aparente o de la experiencia inmediata del mundo.

Rulfo se proyecta en la literatura mexicana a través de sus personajes angustiados y sin ninguna clase de fe; percibiendo tierras secas que no otorgan el sustento del hombre, haciendo contacto con el polvo que levanta un viento sin sentido, viviendo la soledad y miserias mudas de los hombres del campo.

En lo rulfiano, la tragedia es algo cotidiano, muy especialmente en El llano en llamas. Así, encontramos al lado de esta tragedia, o como parte de ésta, el cierre de las posibilidades agrarias, la miseria, el aislamiento geográfico, los caciques, el abandono del Centro, la ausencia de conocimientos técnicos, las supersticiones, el fanatismo, el encierro, etc. Se padece la fatalidad, y se es víctima del determinismo y el destino ciego.

Rulfo, en "Nos han dado la tierra", establece niveles literarios, históricos y culturales, que evitan una lectura parcial, que puede ir de lo estrictamente estructural, pasando por lo sociológico o psicológico, y terminando en lo estrictamente estético. Asimismo, si la obra de Rulfo ha sido reconocida como obra de mérito, ello se debe a la imbricación de los planos de la realidad y del mito. En un primer nivel, existe un referente de tipo social que permea el corpus rulfiano; en un segundo, la posibilidad de interpretación se localiza en poder hacer trascender el primer intento de comprensión que hemos hecho al plano del mito. Es decir, si concebimos que en un plano de la realidad inmediata es posible analizar el texto en la perspectiva de la miseria física, entonces, a esto corresponde la posibilidad de 


\section{ARTÍCULOS}

llegar a otro nivel de interpretación sustentado en el concepto de miseria metafísica que incluye la apreciación del aspecto mítico en el cuento.

\section{Referencias}

Libro del Génesis, en La Nueva Biblia Latinoamericana (1972). Madrid, Ediciones Paulinas/ Verbo Divino.

Galeano, Eduardo (1971). Las venas abiertas de América Latina. México, Siglo XXI.

Harss, Luis. (2003) Juan Rulfo o la pena sin nombre, en La ficción de la memoria: Juan Rulfo ante la crítica, Campbell, Federico (ed). México. UNAM/ Era.

Jiménez de Báez, Yvette (1990). Juan Rulfo: del páramo a la esperanza. Una lectura crítica de su obra. México, FCE.

Jofré, Manuel (1990). Teoría literaria y semiótica. Santiago de Chile, Editorial Universitaria de la Universidad de la Serena.

López Mena, Sergio (1993). Los caminos en la creación de Juan Rulfo. México, UNAM.

López Quintás, Alfonso (1982). Análisis estético de obras literarias. Madrid, Nancea, S. A. de Ediciones.

Martínez Carrizales, Leonardo (1998). Juan Rulfo ante la crítica literaria-periodística de México.México, FCE, 1998.

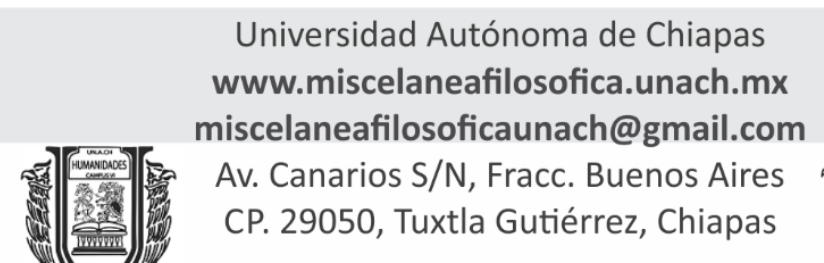


| Cuatrimestral Facultad de Humanidades Campus VI Reserva de Derechos al Uso Exclusivo No.: 04-2018-060814012200-203| ISSN: 2594-1755

Año II | Número 5 | Enero- Abril 2019

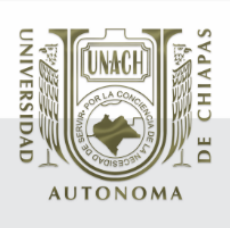

\section{ARTÍCULOS}

Monsiváis, Carlos. Juan Rulfo: declaración de bienes. http://www.jornada.unam.mx/1996/05/05/MONSI000-071.html

Pacheco, José Emilio. Los relatos de Rulfo son ficciones que dejan un sabor de realidad. http://www.sololiteratura.com/rul/rullosrelatosde.htm

Reis, Carlos (1989). Fundamentos y técnicas del análisis literario. Madrid, Gredos.

Reyes, Alfonso (1984). La experiencia literaria. Ensayos sobre experiencia, exégesis y teoría de la literatura. Barcelona, Bruguera.

Rulfo, Juan (1953). El llano en llamas. México, FCE. 